\title{
Thunderstorm and lightning characteristics associated with sprites in Brazil
}

\author{
O. Pinto Jr., M. M. F. Saba, I. R. C. A. Pinto, F. S. S. Tavares, K. P. Naccarato, \\ and N. N. Solorzano \\ National Institute of Space Research (INPE), São Jose dos Campos, Sao Paulo, Brazil
}

M. J. Taylor and P. D. Pautet

Space Dynamics Laboratory, Utah State University, Logan, Utah, USA

\author{
R. H. Holzworth \\ Department of Earth and Space Sciences, University of Washington, Seattle, Washington, USA
}

Received 14 April 2004; revised 25 May 2004; accepted 9 June 2004; published 14 July 2004.

[1] A study of the thunderstorm and cloud-ground lightning characteristics associated with sprite events observed in Brazil is presented. The study is based on ground and aircraft sprite observations with high sensitivity intensified CCD cameras of six different thunderstorms, GOES satellite infrared images, radar and lightning network data. A total of eighteen transient optical events were recorded at three different days in 2002 and 2003, sixteen of which exhibited vertical structures typically associated with sprites. Four thunderstorms were associated with two different cold fronts, one with a Mesoscale Convective System, and one was a local isolated thunderstorm. The sprites occurred during time periods when the percentage of positive flashes was higher than the average percentage for the storm lifetime. The lightning associated with the sprite events was all positive flashes with a mean peak current higher than the mean value for all flashes in the storms. INDEX TERMS: 3304 Meteorology and Atmospheric Dynamics: Atmospheric electricity; 3314 Meteorology and Atmospheric Dynamics: Convective processes; 3324 Meteorology and Atmospheric Dynamics: Lightning; 3334 Meteorology and Atmospheric Dynamics: Middle atmosphere dynamics (0341, 0342). Citation: Pinto, O., Jr., M. M. F. Saba, I. R. C. A. Pinto, F. S. S. Tavares, K. P. Naccarato, N. N. Solorzano, M. J. Taylor, P. D. Pautet, and R. H. Holzworth (2004), Thunderstorm and lightning characteristics associated with sprites in Brazil, Geophys. Res. Lett., 31, L13103, doi:10.1029/2004GL020264.

\section{Introduction}

[2] Since the first documented observation of sprites by Franz et al. [1990], optical observations of sprites have been carried out around the world. A review of the principal observations is given by Rodger [1999]. In the South America, however, only a few evidences have been reported. The first observations were made by Sentman et al. [1995b] with a camera on an airplane near Peru, and by Boeck et al. [1995] from the Space Shuttle. Sentman et al. [1995a] found from 25 groups of events that the sprites were similar to those reported previously in the United States. More recently, Blanc et al. [2004] have reported sprite observations over Brazil using a camera on the ISS and Israelevich et al. [2004] have reported observations of ELVES also in Brazil during the MEIDEX experiment (no sprite observations were done - Yoav Yair, private communication).

[3] Considering that a recent evidence seems to suggest that the South America is one of the main regions in terms of sprite occurrences [Sato and Fukunishi, 2003], more information on sprites in this region can be very important to evaluate their impact on the global circuit. With this goal, the Brazilian Institute of Space Research have initiated in 2002 a campaign to observe sprites and other atmospheric related parameters in Brazil (R. H. Holzworth et al., Strong electric fields from positive lightning strokes in the stratosphere, submitted to Geophysical Research Letters, 2004). The observations during this campaign are the first observations of sprites in Brazil from cameras on ground and airplanes.

[4] In addition, the thunderstorm and lightning characteristics associated with sprites have also been extensively studied by several authors [e.g., Lyons, 1996; Lyons et al., 2002, 2003; Tavares et al., 2003]. In general, they found that most sprites are associated with positive cloud-toground (CG) flashes with peak current values from $10 \mathrm{kA}$ to more than $100 \mathrm{kA}$. For a given storm, however, they found that the average intensity of the parent flashes tends to be larger than the average of all positive flashes of the storm. For the previous South American sprite observations, however, no lightning data were available.

[5] In this paper, the lightning characteristics associated with six thunderstorms that produce 18 transient optical events were analyzed. The 18 events were recorded at three different days in 2002 and 2003 by the Utah State University team; 16 exhibited vertical structures typically associated with sprites, while the other two were disc-like events, characteristic of sprite halo or elves. All events appear just in one or two consecutive frames, implying that the duration of the events were shorter than $66 \mathrm{~ms}$, and occur in the mature-to-late stages of the storms. Figure 1 shows an example of a sprite recorded in 25 November 2002 at 02:49 UT. Table 1 summarizes all information related to the 18 events, including date, time of the sprite in UT, peak current of the causative positive flash ( 14 cases), sprite type, location of the camera and storm identification number. The lightning data were obtained by a network of 


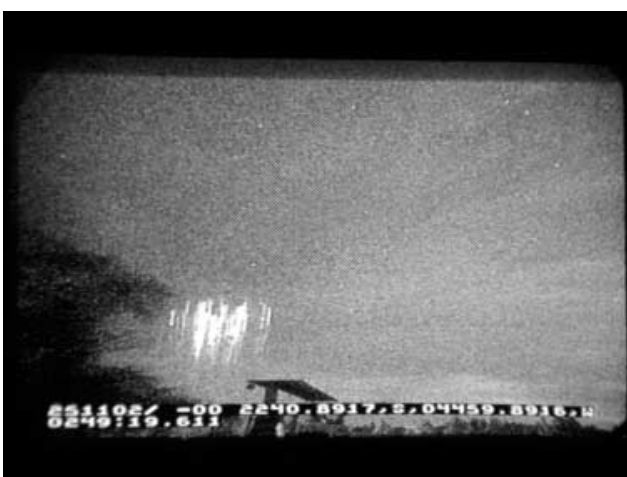

Figure 1. An example of sprite recorded in 25 November 2002 at 02:49 UT in the Southeast of Brazil. See color version of this figure in the HTML.

23 Impact and LPATS sensors located in the Southeast and surrounding regions of Brazil. In all cases in Table 1 that a sprite-parent lightning was identified, the delay time between the time of the sprite and the time of the lightning event was lower than $10 \mathrm{~ms}$.

\section{Lightning Data}

[6] The lightning data used in this study were obtained by a lightning network covering the entire Southeast region and part of the South and Center regions of Brazil [see Pinto et al., 1999a, 1999b, 2003]. At the time of the observations, the network was composed by 23 sensors (7 Impact and 16 LPATS sensors). Considering that this type of network is subject to contamination by intra-cloud flashes, mainly in the case of positive CG flashes, in this work we have only considered positive CG flashes with peak current larger than $10 \mathrm{kA}$ [Cummins et al., 1998]. The data were analyzed in terms of strokes, not considering any algorithm to combine them into flashes, except for the flash rate that was calculated not taken into account the detection efficiency of the network in the region of study (estimated in $80 \%$ ).

\section{Results and Discussion}

[7] Figure 2 shows for some of the events reported in Table 1 the related infrared satellite GOES images and

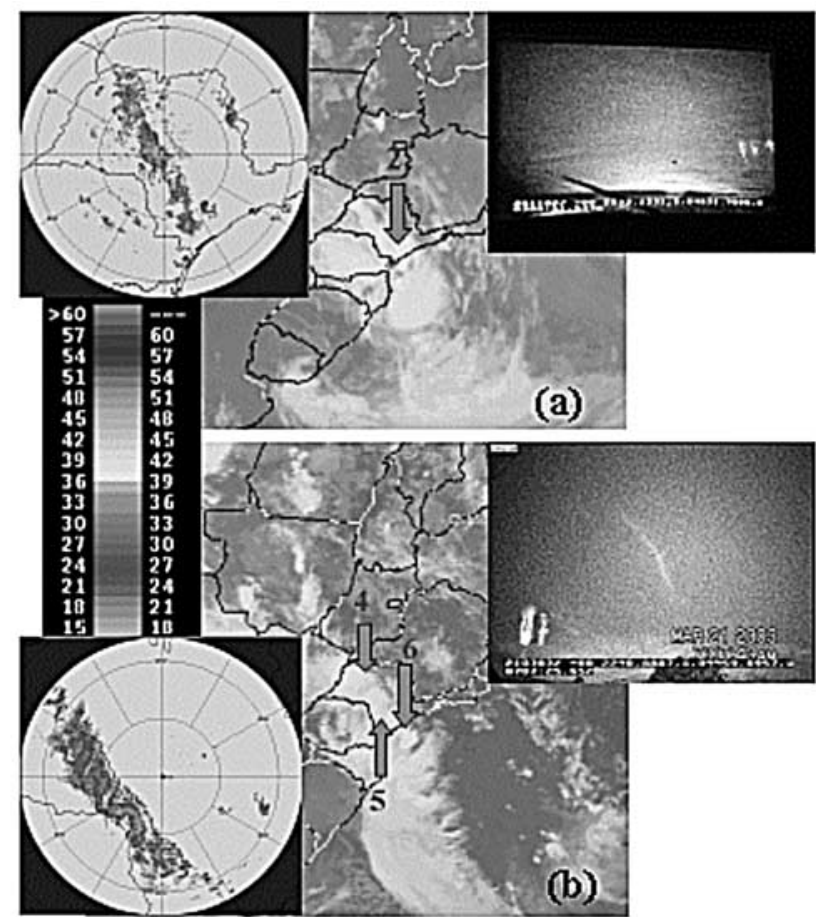

Figure 2. Infrared satellite GOES images of (a) thunderstorm 2 (at 03:09 UT), and (b) thunderstorms 4, 5 and 6 (at 06:00 UT), all of them associated with cold fronts. The sprite images are shown for case 2, taken from an airplane, and for case 4, on the ground. The PPI data from the radar of Bauru are also shown at 03:00 (in a $450 \mathrm{~km}$ range) and 06:00 UT (in a $250 \mathrm{~km}$ range), respectively. See color version of this figure in the HTML.

reflectivity data, from the meteorological radar located in Bauru (geographic coordinates 22,3S, 49W). The numbers in red identify the storm; the sprite images are also shown. While storms 2, 4, 5 and 6 (shown in Figure 2) are related to cold fronts, storm 1 was related to a Mesoscale Convective System (MCS) and storm 3 was a local air mass thunderstorm. For all cases studied, the characteristics of the thunderstorms associated with sprites (diameter, radar-echo area above $15 \mathrm{dBz}$, maximum reflectivity, cloud top and

Table 1. Summary of the Sprite Events Reported in the Southeastern Brazil

\begin{tabular}{|c|c|c|c|c|c|c|}
\hline Sprite Event & Date (UT) & Time (UT) & Peak Current (kA) & Sprite Type & Location (of the Camera) & Storm No. \\
\hline 1 & $11 / 25 / 02$ & $2: 49.19 .611$ & 41 & Column Sprite & ground & 1 \\
\hline 2 & $11 / 25 / 02$ & $2: 52.15 .022$ & 45 & Unit Sprite & ground & 1 \\
\hline 4 & $11 / 26 / 02$ & $3: 03.07 .524$ & 44 & Cluster Sprite & aircraft & 2 \\
\hline 5 & $11 / 26 / 02$ & $3: 08.51 .471$ & 122 & Cluster Sprite & aircraft & 2 \\
\hline 6 & $11 / 26 / 02$ & $3: 09.50 .63$ & & Carrot Sprites & aircraft & 2 \\
\hline 9 & $3 / 21 / 03$ & $5: 52.19 .449$ & 150 & Sprite (Fuzzy) & ground & 4 \\
\hline 10 & $3 / 21 / 03$ & $6: 06.54 .79$ & 93 & Cluster Sprite & ground & 4 \\
\hline 11 & $3 / 21 / 03$ & $6: 10.45 .13$ & & Carrot Sprites & ground & 4 \\
\hline 12 & $3 / 21 / 03$ & $6: 22.19 .74$ & 101 & Sprite Halo or Elve? & ground & 4 \\
\hline 13 & $3 / 21 / 03$ & $6: 32.39 .63$ & 146 & Sprite Halo or Elve? & ground & 5 \\
\hline 14 & $3 / 21 / 03$ & $6: 36.15 .93$ & 28 & Dancing Sprite & ground & 4 \\
\hline 18 & $3 / 21 / 03$ & $7: 14.41 .592$ & 26 & Carrot Sprites & ground & 6 \\
\hline
\end{tabular}


Table 2. Summary of the Positive CG Flashes During the Sprite Events

\begin{tabular}{|c|c|c|c|c|}
\hline Storm No. & $\begin{array}{c}\text { Total NO. +CG } \\
\text { (in a } 20 \text { min. } \\
\text { Interval Centered } \\
\text { in the Sprite Event) }\end{array}$ & $\begin{array}{l}\text { Percentage of }+\mathrm{CG} \\
\text { (in a } 20 \text { min. } \\
\text { Interval Centered } \\
\text { in the Sprite Event) }\end{array}$ & $\begin{array}{c}\text { Average } \\
\text { Peak Current } \\
(\mathbf{k A}) \\
(\mathrm{All}+\mathrm{CG}) \\
\end{array}$ & $\begin{array}{c}\text { Average } \\
\text { Peak Current } \\
\text { (kA) } \\
\text { (Sprite-Associated +CG) } \\
\end{array}$ \\
\hline 1 & 25 & 47 & 28 & 43 \\
\hline 2 & 11 & 78 & 48 & 66 \\
\hline 3 & 5 & 42 & 21 & 29 \\
\hline 6 & 8 & 36 & 34 & 27 \\
\hline
\end{tabular}

duration), as estimated from the satellite and radar information, were not significantly different from the typical values for these kind of thunderstorms in this region. The diameter varied from tens to a few hundreds of kilometers, the radar-echo areas above $15 \mathrm{dBz}$ were below $10,000 \mathrm{~km}^{2}$ (considering just the individual cells producing sprites, not the entire contiguous echo), the maximum reflectivities were marginally above $40 \mathrm{dBz}$, the cloud tops were below $12 \mathrm{~km}$ and the duration of the storms were below 2 hours. In two cases, the radar-echo area was just $5000 \mathrm{~km}^{2}$, characteristic of small storms. The total lightning activity of the thunderstorms was also investigated. For all events the flash rate was always below 10 flashes per minute.

[8] Table 2 shows for the different thunderstorms the average peak current of all positive flashes in 20-min. time intervals centered in the sprite events, compared with the peak current of the sprite-associated flashes. Sprite-associated positive flashes have substantially larger average peak currents than the average of the remaining positive population around the events, in agreement with the results reported by Lyons [1996]. For all events, the peak current of the sprite-parent positive flashes average $71 \%$ higher than the other positive flashes. Also shown in the second column of Table 2 is the percentage of positive strokes during the 20 -min. interval centered in the sprite event. The percentage values are much higher than the values for the whole life of the storms (from $10 \%$ to $15 \%$ ). Due to incomplete observation of the storms along their life times, no estimate about the "sprite efficiency" of the storms, that is, the number of sprite-associated positive flashes divided by the total number of positive flashes, was obtained.

\section{Conclusions}

[9] Observations of sprites associated with six different thunderstorms (two related to cold fronts, one related to a MCS, and one a local isolated event) were conducted with cameras on ground and airplanes for the first time in the Southeast Brazil during the end of 2002 and early 2003. Based on the usual characteristics of the sprite-producing thunderstorms, the results suggest that may occur more frequently than has previously observed over U.S., in agreement with other observations [Neubert et al., 2001] and indicated that sprites are apparently common in this region of Brazil. More observations, however, are need to verify the estimates recently reported by Sato and Fukunishi [2003], indicating that the South America may be one of the most active regions of sprite occurrences in the world. All sprite events were associated with positive
CG flashes with average peak current larger than the average peak current of the positive CG population in the same storms, in agreement with other observations in the United States. Also, they occur during time periods when the percentage of positive flashes in the storm is much higher than the average percentage for the whole life of the storm.

[10] Acknowledgments. We are indebted with our colleagues E.C. Ferraz, E.R. dos Santos, J.O. Fernandes, and R.V. Corrêa of INPE, M. Bailey of Utah State University and J. N. Thomas and M. P. McCarthy of University of Washington for help us during the data acquisition. The authors would like also to thanks the Fundacão de Amparo à Pesquisa do Estado de São Paulo (FAPESP) for supporting this research through the project 02/01329-1. The first author would also to thank the Conselho Nacional de Desenvolvimento Científico e Tecnológico (CNPQ) for personal support.

\section{References}

Blanc, E., T. Farges, R. Roche, D. Brebion, T. Hua, A. Labarthe, and V. Melnikov (2004), Nadir observations of sprites from the International Space Station, J. Geophys. Res., 109, A02306, doi:10.1029/ 2003JA009972.

Boeck, W. L., O. H. Vaughan Jr., R. J. Blakeslee, B. Vonnegut, M. Brook, and J. McKune (1995), Observations of lightning in the stratosphere, J. Geophys. Res., 100, 1465-1475.

Cummins, K. L., M. J. Murphy, E. A. Bardo, W. L. Wiscox, R. B. Pyle, and A. E. Pifer (1998), A combined TOA/MDF technology upgrade of the U.S. National lightning detection network, J. Geophys. Res., 103, 90359044.

Franz, R. C., R. J. Nemzek, and J. R. Winckler (1990), Television image of a large upward electrical discharge above a thunderstorm system, Science, 249, 48-51.

Israelevich, P. L., Y. Yair, A. D. Devir, J. H. Joseph, Z. Levin, I. Mayo, M. Moalem, C. Price, B. Ziv, and A. Sternlieb (2004), Transient airglow enhancements observed from the space shuttle Columbia during the MEIDEX sprite campaign, Geophys. Res. Lett., 31, L06124, doi:10.1029/2003GL019110.

Lyons, W. A. (1996), Sprite observations above the U.S. High Plains in relation to their parent thunderstorm systems, J. Geophys. Res., 101, $29,641-29,652$

Lyons, W. A., E. R. Williams, S. A. Cummer, and M. A. Stanley (2002), 3-D lightning characteristics of High Plains sprite-producing storms, paper presented at 17th International Lightning Detection Conference, Vaisala, Tucson, Ariz.

Lyons, W. A., T. E. Nelson, E. R. Williams, S. A. Cummer, and M. A. Stanley (2003), Characteristics of sprite-producing positive cloud-toground lightning during the 19 July 2000 STEPS Mesoscale Convective Systems, Mon. Weather Rev., 131, 2417-2427.

Neubert, T., T. H. Allin, H. Stenbaek-Nielsen, and E. Blanc (2001), Sprites over Europe, Geophys. Res. Lett., 28, 3585-3588.

Pinto, O., Jr., I. R. C. A. Pinto, M. A. S. S. Gomes, A. L. Padilha, I. Vitorello, J. H. Diniz, A. M. Carvalho, and A. Cazetta Filho (1999a), Cloud-toground lightning in the southeastern Brazil in 1993: 1. Geographical distribution, J. Geophys. Res., 104, 31,369-31,379.

Pinto, I. R. C. A., O. Pinto Jr., R. M. L. Rocha, J. H. Diniz, A. M. Carvalho, and A. Cazetta Filho (1999b), Cloud-to-ground lightning flashes in the southeastern Brazil in 1993: 2. Time variations and flash characteristics, J. Geophys. Res., 104, 31,381-31,387.

Pinto, O., Jr., I. R. C. A. Pinto, J. H. Diniz, A. Cazetta Filho, A. M. Carvalho, L. C. L. Chechiglia, and G. E. Amorin (2003), A long-term 
study of the lightning flash characteristics in the southeastern Brazil, J. Atmos. Solar Terr. Phys., 65, 739-748.

Rodger, C. J. (1999), Red sprites, upward lightning, and VLF perturbations, Rev. Geophys., 37, 317-336.

Sato, M., and H. Fukunishi (2003), Global sprite occurrence location and rates derived from triangulation of transient Schumann resonance events, Geophys. Res. Lett., 30(16), 1859, doi:10.1029/2003GL017291.

Sentman, D. D., E. M. Wescott, D. L. Osborne, D. L. Hampton, and M. J. Heavner (1995a), Preliminary results from the Sprites94 campaign: 1. Red sprites, Geophys. Res. Lett., 22, 1205-1208.

Sentman, D. D., E. M. Wescott, D. L. Osborne, M. J. Heavner, and D. L. Hampton (1995b), The Peru95 sprite campaign: Overview, Eos Trans. $A G U, 76(17)$, Spring Meet. Suppl., S66.

Tavares, F. S. S., D. D. Sentman, E. M. Wescott, O. Pinto Jr., O. Mendes Jr., and M. J. Taylor (2003), Statistical analysis of space-time relation- ships between sprites and lightning, J. Atmos. Solar Terr. Phys., 65, $525-536$.

R. H. Holzworth, Department of Earth and Space Sciences, University of Washington, 346A Johnson Hall, Box 351650, Seattle, WA 98195-1650, USA.

K. P. Naccarato, I. R. C. A. Pinto, O. Pinto Jr., M. M. F. Saba, N. N. Solorzano, and F. S. S. Tavares, National Institute of Space Research (INPE), Av. dos. Astronautas, 178, Caixa Postal 515, São Jose dos Campos, Sao Paulo 12201, Brazil. (osmar@dge.inpe.br)

P. D. Pautet and M. J. Taylor, Space Dynamics Laboratory, Utah State University, Logan, UT 84322-4145, USA. 